\title{
Multiprofessioneel onderwijs: een haalbaarheidsonderzoek
}

\author{
A.M.M. Verbeek-Weel, J.C.M. Metz
}

\section{Samenvatting}

Inleiding: In de huidige, complexe gezondheidszorg is goede samenwerking tussen artsen, verpleegkundigen en paramedici een van de belangrijkste factoren die de kwaliteit van zorg voor de patiënt bepalen. Optimale zorgverlening wordt vaak belemmerd door communicatieproblemen en het onvoldoende op de hoogte zijn van elkaars deskundigheden en competenties. Multiprofessioneel onderwijs (MPO) gericht op multidisciplinaire samenwerking en communicatie tijdens de initiële beroepsopleidingen lijkt daarom een aantrekkelijke optie. Dit artikel is gebaseerd op het rapport van een vooronderzoek naar de haalbaarheid van MPO in Nederland.

Methode: In het voorjaar van 1998 is literatuuronderzoek gedaan, zijn interviews en een enquête afgenomen en is een werkbezoek gebracht aan de Universiteit van Linköping in Zweden.

Resultaten: Multiprofessioneel onderwijs wordt gezien als een mogelijkheid voor studenten om te leren in teams te werken. Er is voldoende draagvlak om in Nederland meer ervaring op te doen.

Discussie: Op grond van de resultaten is aanbevolen om na te gaan welke mogelijkheden er in Nederland bestaan om MPO te ontwikkelen. In april 1999 is subsidie aangevraagd en verkregen voor het ontwikkelen en uitvoeren van een multiprofessioneel onderwijstraject voor studenten aan gezondheidszorgopleidingen in instellingen voor wetenschappelijk en hoger beroepsonderwijs. (Verbeek-Weel AMM, Metz JCM. Multiprofessioneel onderwijs: een haalbaarheidsonderzoek. Tijdschrift voor Medisch Onderwijs 2001:20(4): 140-146.)

\section{Inleiding}

In de huidige, complexe gezondheidszorg is goede samenwerking tussen artsen, verpleegkundigen en paramedici een van de belangrijkste factoren die de kwaliteit van zorg voor de patiënt bepalen. Voorwaarde voor een goede samenwerking is dat werkers in de gezondheidszorg van elkaars deskundigheden en competenties op de hoogte zijn, zodat de juiste zorgverleners steeds op het juiste moment bij de patiëntenzorg betrokken kunnen worden. Een optimale zorgverlening wordt vaak belemmerd door communicatieproblemen. Multiprofessioneel onderwijs (MPO) gericht op multidisciplinaire samenwerking en communicatie tijdens de initiële beroepsopleidingen, zowel in het wetenschappelijk als het hoger beroepsonderwijs, lijkt een aantrekkelijke optie om samenwerken in de zorg te verbeteren. In het voorjaar van 1998 heeft het Nijmeegs Instituut voor Kennisoverdracht Gezondheidszorg (NIKOG) met subsidie van het Ministerie van Volksgezondheid, Welzijn en Sport (VWS) een vooronderzoek gedaan naar de haalbaarheid van het ontwikkelen, implementeren en evalueren van MPO. Het NIKOG is een samenwerkingsverband van het Academisch Ziekenhuis Nijmegen (AZN), de Faculteit der Medische Wetenschappen (FMW) van de Katholieke Universiteit Nijmegen (KUN) en de Hogeschool van Arnhem en Nijmegen (HAN). 
Het vooronderzoek had een looptijd van vier maanden en is uitgevoerd door het Klinisch Trainingscentrum (FMW/KUN). Doel was antwoord te krijgen op een aantal vragen over:

- de definitie van MPO en gerelateerde begrippen;

- de legitimering van MPO;

- onderwijsactiviteiten in Nederland en in het buitenland en ervaringen op het gebied van MPO;

- de behoefte aan en het draagvlak voor MPO in Nederland.

Dit artikel geeft een beknopte beschrijving van de belangrijkste gegevens uit het eindrapport van het onderzoek.

\section{Methode}

Het vooronderzoek omvatte in eerste instantie een literatuuronderzoek, waarbij gezocht is aan de hand van de trefwoorden multiprofessioneel/multidisciplinair, interprofessioneel/interdisciplinair onderwijs en via literatuurverwijzingen. Vervolgens is een werkbezoek gebracht aan de Universiteit van Linköping (Zweden) en is een aantal deskundigen en betrokkenen geïnterviewd. Op 20 maart 1998 werd in Nijmegen, onafhankelijk van het vooronderzoek, het symposium 'multidisciplinaire samenwerking in de geriatrie: kakofonie of harmonie?' gehouden. Van deze gelegenheid is gebruik gemaakt om aan de deelnemers aan het symposium een korte enquête over MPO voor te leggen.

\section{Resultaten}

\section{Definitie}

Als het gaat om MPO worden in de literatuur verschillende termen door en naast elkaar gebruikt. In het kader van het vooronderzoek is gekozen voor de definitie van de World Health Organization (WHO). Zij definieert MPO als: "The process by which a group of students (or workers) from the health-related occupations with different educational backgrounds learn together during certain periods of their education, with interaction as an important goal, to collaborate in providing promotive, preventive, curative, rehabilitative and other health-related services". ${ }^{1}$ In deze definitie wordt enerzijds het belang van interactie verwoord en anderzijds het belang van het gezamenlijk volgen van onderwijs gedurende bepaalde perioden van de opleiding.

\section{Legitimering}

\section{Ontwikkelingen in de gezondheidszorg}

De afgelopen decennia is kennis over ziekten, hun beloop en behandeling enorm toegenomen. Er zijn vele nieuwe onderzoeks- en behandeltechnieken ontwikkeld. Het terrein van de geneeskunde en de zorg is zo omvangrijk en complex dat sterke specialisatie noodzakelijk is geworden. ${ }^{2}$ Het leveren van zorg op maat, het ontwikkelen van integrale zorg- en behandelplannen vereist nauwe samenwerking tussen werkers in de gezondheidszorg. Om goed te kunnen samenwerken moeten zij op de hoogte zijn van elkaars deskundigheden en rollen.

\section{Overheidsbeleid}

Ook de overheid ziet de noodzaak van een nauwere samenwerking tussen werkers in de gezondheidszorg. Het rapport 'Gedeelde zorg, betere zorg', dat in 1994 gepresenteerd werd door de Commissie Modernisering Curatieve Zorg, is hier een uiting van. ${ }^{3}$ De patiënt kreeg een centrale plaats toegewezen in de gezondheidszorg, wat betekent dat echelons met hun eigen regels plaats moeten maken voor een continuüm van zorg. ${ }^{4}$ In 1998 is een discussienota gepubliceerd met als onderwerp een regionaal zorgnetwerk voor transmurale zorg. 
Uitgangspunt is de volgende visie op de zorg: "De zorg wordt bepaald door de vraag van de patiënt, niet door de muren van de zorg". 4 Voorheen was de plaats waar een patiënt zich bevond, bepalend voor wie de zorg leverde. Zorg op maat is alleen mogelijk door het ontkoppelen van enerzijds generalistische zorg en de thuissituatie en anderzijds specialistische zorg en het ziekenhuis. In de vorm van transmurale zorg ontstaat een aangepaste samenstelling van generalistische zorg, specialistische zorg en intra- en extramurale faciliteiten. Het samenwerkingsverband is verantwoordelijk voor de zorg en niet één van de behandelaars. Op deze manier kunnen alle werkers in de gezondheidszorg zich toeleggen op hun kernactiviteiten: de taken waarin men zich werkelijk bekwaamd heeft. Deze werkwijze werkt inspirerend en motiverend en sluit aan bij de professionele kwaliteiten van werkers in de gezondheidszorg. ${ }^{4}$

\section{Gezondheidszorgonderwijs}

MPO heeft, indien het vanaf het begin in de curricula wordt geprogrammeerd, een positieve invloed op het toekomstig functioneren in teams. Het verkleint het risico dat studenten gevangen worden in een conventionele professionele rol. Het meest in het oog springende voordeel van MPO is het bevorderen van het teamconcept, waardoor wederzijds respect en begrip ontstaat en studenten in staat worden gesteld kennis en vaardigheden te delen. 56

Een concreet voorbeeld van werken in een team is palliatieve zorg. Om deze palliatieve (thuis)zorg goed te kunnen verlenen zijn continuïteit, complementariteit van taken, coördinatie en communicatie van groot belang. Dit geldt zowel voor de samenwerking binnen de eerste lijn (tussen huisarts en verpleegkundige) als voor de samenwerking tussen de eerste en de tweede lijn (tussen huisarts en specialist en tussen wijkverpleegkundige en ziekenhuisverpleegkundige). ${ }^{7}$

\section{Knelpunten bij de invoering van MPO}

Belemmerende factoren bij de invoering van MPO hebben enerzijds te maken met de attitude van professionals ten opzichte van andere professies en anderzijds met de organisatie van het onderwijs. De eigen professie wordt nogal eens als allerbelangrijkst ervaren en er is nog te vaak te weinig achting voor elkaars professionaliteit. Opleidingen zijn in alle opzichten streng gescheiden en kaders en middelen voor samenwerking ontbreken volledig. 89

\section{MPO-activiteiten in Nederland en in het buitenland}

In Nederland is recent een aantal initiatieven genomen op het gebied van MPO. Ze voldoen echter niet aan de WHO-definitie van interactief leren en komen niet voort uit een gefundeerde visie op wenselijke ontwikkelingen in de gezondheidszorg. Meestal betreft het kostenbesparende overwegingen. ${ }^{10}$

In Europa zijn er met name in GrootBrittannië en Scandinavië veel universiteiten die MPO verzorgen in de vorm van na- en bijscholing. ${ }^{11}$ Ook in de Verenigde Staten en Canada zijn de laatste twee decennia soortgelijke ontwikkelingen gaande. ${ }^{12}$ Het meest beschreven in de literatuur is echter het MPO dat sinds 1986 aan de Universiteit van Linköping in Zweden wordt gerealiseerd. In mei 1998 is een werkbezoek aan Linköping gebracht.

\section{Werkbezoek aan de universiteit van Linköping}

Aan de Faculteit Gezondheidswetenschappen van de Universiteit van Linköping studeren ongeveer 1200 studenten, verdeeld over de studierichtingen geneeskunde, verpleegkunde, fysiotherapie, ergotherapie en maatschappelijk werk. Ook 
biomedische analisten worden binnen deze faculteit opgeleid. De studenten worden opgeleid volgens de principes van studentgericht, probleemgestuurd en geïntegreerd onderwijs. Een belangrijk aspect van deze opleidingen is de voorbereiding van de studenten op teamwork tijdens hun latere beroepsuitoefening: samen leren teneinde later samen te kunnen werken. Regelmatig volgen studenten van de verschillende gezondheidszorgopleidingen daarom gemeenschappelijke curriculumonderdelen. Dit betreft in het begin van het eerste jaar een introductieblok 'Man and society' van tien weken. De studenten volgen dit blok in tutorgroepen van zeven studenten uit de verschillende opleidingstrajecten. Men duidt dit aan met de term shared learning, omdat in deze periode nog niet echt sprake is van multiprofessionele training. Niettemin worden door het gemeenschappelijk volgen van deze module de voorwaarden geschapen voor kennisname van elkaars invalshoeken en wordt wederzijds begrip gevormd, waarop in latere fasen van de studie kan worden voortgebouwd. In de latere jaren van de studie vinden soortgelijke gemeenschappelijke blokken plaats op het gebied van rampengeneeskunde, resuscitatie en ethiek. 1314

Op heel bijzondere wijze komt MPO tot uitdrukking in Training Ward 30. Dit is een onderafdeling van de orthopedische kliniek van het academisch ziekenhuis, die van de rest van de afdeling is afgesplitst om MPO te kunnen realiseren. De afdeling bevat acht bedden, die hoofdzakelijk bezet worden door geselecteerde patiënten: doorgaans oudere patiënten met heupfracturen, soms ook door patiënten met een amputatie of heup- of knieprothese. Sinds 1996 ligt de patiëntenzorg op deze afdeling - onder supervisie van professionele beroepsbeoefenaren (orthopeden, verpleegkundigen, fysio- en ergotherapeuten) - in handen van multidisciplinair samengestelde teams van gevorderde studenten in de betreffende studierichtingen. Alle studenten werken gedurende twee weken in een dergelijk team. De stage op Training Ward 30 vindt plaats in het tiende semester van alle participerende opleidingen. Daarna volgt voor de geneeskundestudenten anderhalf jaar met praktijkstages. De andere opleidingen worden kort na de Ward-30stage afgerond. De stage vindt plaats terwijl het andere onderwijs gewoon doorgaat. Dit minimaliseert de planningsproblemen en blijkt voor de studenten geen problemen op te leveren. Voor het inhalen van het gemiste reguliere onderwijs zijn geen speciale maatregelen getroffen; studenten dragen hiervoor zelf zorg. Gedetailleerde informatie over de gang van zaken van dit unieke MPO-experiment op Ward 30 is te lezen in het rapport 'Naar multiprofessioneel onderwijs in de gezondheidszorg; een onderzoek naar de haalbaarheid'. 10

\section{De behoefte aan en het draagulak voor $\mathrm{MPO}$ in Nederland}

\section{Interviews met deskundigen en betrokkenen}

Om inzicht te krijgen in het draagvlak voor een multiprofessioneel onderwijsprogramma, is een twaalftal sleutelfiguren geselecteerd voor een interview. In de eerste plaats betrof dit de haalbaarheid binnen de Nijmeegse gezondheidszorgopleidingen (geneeskunde en hbo-opleidingen). Daarnaast zijn personen geïnterviewd die inzicht konden verschaffen in de mate waarin multiprofessioneel opleiden wenselijk wordt geacht. Op grond van deze uitgangspunten zijn sleutelfiguren geselecteerd die betrokken waren bij beroepspraktijk en onderwijs, bij onderzoek en beleid, of die inzicht hadden in klachten van patiënten. 
De interviews zijn op een gestructureerde en gerichte manier afgenomen. Na het maken van de afspraak is een beknopte projectomschrijving toegestuurd en een vragenlijst die hoofdzakelijk uit gesloten vragen bestond. Verzocht werd deze lijst voorafgaand aan het interview in te vullen. De geïnterviewde kon zich zo alvast een beeld en een mening vormen over MPO, waardoor tijdens het interview dieper kon worden ingegaan op de motieven en argumenten van de geïnterviewden.

In de interviews werd het feit dat men te weinig inzicht heeft in elkaars deskundigheden genoemd als belangrijkste knelpunt bij multidisciplinaire samenwerking. Daardoor weet men niet wanneer andere disciplines geraadpleegd moeten worden en wordt een goede afstemming belemmerd. Winstpunten van multidisciplinair samenwerken zijn vooral een verbetering van de kwaliteit en efficiëntie van de patiëntenzorg. Alle geïnterviewden waren bekend met MPO en de meesten van hen hadden er ook ervaring mee. MPO tijdens de initiële beroepsopleidingen wordt als zeer belangrijk gezien en moet op meerdere momenten in het curriculum gepland worden.

\section{Enquête}

Aan de deelnemers aan het eerder genoemde symposium over multidisciplinaire samenwerking in de geriatrie is een enquête voorgelegd. De enquête bestond uit twee delen: vier open vragen en één gesloten vraag over multidisciplinair samenwerken (dit betrof een al geplande enquête vanuit de sectie Klinische Geriatrie van de Nederlandse Vereniging voor Geriatrie) en zeven gesloten vragen over multiprofessioneel opleiden. Zeventig van de ongeveer tweehonderd deelnemers hebben een enquêteformulier ingevuld en ingeleverd. De ervaringen van deelnemers met de multidisciplinaire teambespreking blijken illustratief voor de algemene problematiek op het gebied van samenwerking. Verreweg de meeste respondenten zijn niet tevreden over de manier waarop deze verloopt. Belangrijkste knelpunt is een niet-evenredige inbreng van de verschillende disciplines. Bovendien ervaart men de teambespreking niet als echte samenwerking: er is weinig openheid en respect voor elkaar, het is moeilijk om gemeenschappelijke doelen te formuleren, en men is te veel gericht op de eigen discipline. Om de kwaliteit van de multidisciplinaire teambespreking te verbeteren is het noodzakelijk om echte samenwerking tot stand te brengen. Meer structuur en een betere afstemming op elkaar zijn hierbij belangrijk. De meeste respondenten zijn onbekend met MPO en geven vervolgens aan dat zij het wenselijk achten om tijdens de initiële beroepsopleidingen MPO te organiseren.

\section{Discussie}

Zowel de literatuur als de resultaten van de interviews en de enquête wijzen op het belang van multiprofessionaliteit in het gezondheidszorgonderwijs. De toenemende complexiteit in de organisatie van de gezondheidszorg, de ontwikkelingen in kennis en kunde, de toenemende informatiestromen en de veranderingen in de wetgeving zijn factoren die het werken als solist nauwelijks nog mogelijk maken. Uit het oogpunt van kwaliteit van zorg, waarbinnen doelmatigheid, doeltreffendheid en patiëntgerichtheid van de gevraagde zorg de bepalende begrippen zijn, is het niet meer verantwoord anders dan in een team te werken. Voor veel zorginstellingen is integrale patiëntenzorg een van de beleidsuitgangspunten. Dit houdt in dat alle betrokken disciplines rond de zorg van de patiënt een op elkaar afgestemd behandel/zorgplan dienen te formuleren. Werkers in de gezondheidszorg zijn 
echter tot nu toe niet opgeleid om in een team te functioneren. De nog steeds bestaande verkokering van gezondheidszorgopleidingen, die toch allemaal hetzelfde doel nastreven (de student uitrusten met kennis en vaardigheden die het welzijn van de patiënt bevorderen), beneemt het zicht op een integrale patiëntenzorg, waarbinnen de student kan worden geleerd verder te kijken dan het eigen beroepsdomein.

De geraadpleegde literatuur geeft veel informatie over de strijd die de pioniers hebben moeten voeren met vertegenwoordigers van vooral de medische professie. Niettemin is er een omslag in het denken over belangen van patiënten en van werkers in de gezondheidszorg tot stand gekomen die leidt tot het inzicht dat we afhankelijk zijn van elkaar en die de geclaimde autonomie in een ander perspectief plaatst.

De conclusie is gewettigd, dat MPO in Nederland nog tamelijk onbekend is, maar dat de noodzaak om in de gezondheidszorg sterker te gaan samenwerken nagenoeg unaniem wordt onderschreven. De tijd lijkt dan ook rijp om MPO te gaan ontwikkelen.

\section{Vervolgtraject}

De bevindingen van het vooronderzoek waren aanleiding om subsidie bij het HBO-Vernieuwingsfonds aan te vragen voor een vervolgonderzoek. Inmiddels is op 1 april 1999 het tweejarig innovatieproject Multiprofessioneel onderwijs in de gezondheidszorg van start gegaan. ${ }^{15} \mathrm{Het}$ wordt uitgevoerd door de Faculteit Gezondheidszorg van de HAN in samenwerking met de Faculteit der Medische Wetenschappen (KUN) en het AZN Sint Radboud. Doel van het innovatieproject is het ontwerpen van een leertraject voor studenten van de opleidingen geneeskunde, verpleegkunde en paramedische beroepen, waarin het kunnen samenwerken in de toekomstige beroepspraktijk centraal staat. Aan het eind van het project zullen de participerende opleidingen beschikken over een aantal prototypen van MPO voor zowel de propedeuse als de hoofdfase. Men spreekt van prototypen omdat de te ontwikkelen onderwijseenheden niet alleen ingezet moeten kunnen worden in de opleidingen van de HAN en de KUN. Zij moeten ook overdraagbaar zijn naar andere gezondheidszorgopleidingen met wellicht een andere opzet en structuur. Als projectresultaten worden voorzien:

- Propedeuse:

- module Oriëntatie teamgerichte gezondheidszorg;

- studiedag Oriëntatie gezondheidszorg.

- Hoofdfase:

- module Teamontwikkeling, waarin aan de hand van casuïstiek gezamenlijk behandelplannen worden opgesteld;

- uitgewerkte casuïstiek ten behoeve van het vaardigheidsonderwijs met behulp van simulatiepatiënten, onder andere beschikbaar op cd-rom;

- een model voor een keuzestage, waarin zorgteams van studenten onder supervisie van tutor-experts een afdeling runnen;

- bijscholingsaanbod voor hoger gezondheidszorgonderwijs, verwant wetenschappelijk onderwijs en beroepenveld.

\section{Literatuur}

1. World Health Organization. Learning together to work together for health. Technical Report Series 769. Geneva, Switzerland: World Health Organization; 1988. p. 6-7.

2. Hoefnagels KJL. Specialisten en verpleegkundigen: de pijlers van de ziekenhuiszorg. Een terugblik. Medisch Contact 1997:52(21):651-4.

3. Commissie Modernisering Curatieve Zorg. Gedeelde zorg: betere zorg? 1994.

4. Assmann P, Wieringa GJ, Héman R. De zorgbrug in de regio. Een antwoord op de knelpunten in transmurale zorg [discussienota]. Medisch Contact 1998:53(10):330-3. 
5. Urbina C, Hess D, Andrews R, Hammond R, Hansbarger C. Problem-based learning in an interdisciplinary setting. Family and Community Health 1997:10(1):16-28.

6. Areskog NH. Multiprofessional education at the undergraduate level. In: Soothill K, Mackay L, Webb C, redactie. Interprofessional relations in health care. London: Edward Arnold; 1995.

7. Willems D. Wie doet wat in de palliatieve zorg thuis? [verslag van een conferentie]. Medisch Contact 1997:52(5):167-8.

8. Goble REA. Continuing education for health care professionals [paper presented at the Sixth Annual Conference of EMPE]. Finland: University of Tampere; 1992.

9. Pereira Gray D. The case for multi-professional practice [unpublished paper]. Exeter: University of Exeter, 1989.

10. Verbeek-Weel AMM, Metz JCM, Peters W. Naar multiprofessioneel onderwijs in de gezondheidszorg; een onderzoek naar de haalbaarheid. Nijmegen: NIKOG; 1998.

11. Goble REA. Multi-professional education in Europe: an overview. In: Leathard, redactie. Going inter-professional: working together for health and welfare. London: Routledge; 1994.

12. Casto M. Inter-professional work in the USA education and practice. In: Leathard (redactie). Going inter-professional: working together for health and welfare. London: Routledge; 1994.
13. Wahlström O, Sandén I, Hammar M. Multiprofessional education in the medical curriculum. Med Educ 1997:31:425-9.

14. Wahlström O, Sandén I. Multiprofessional training ward at Linköping University: early experience. Education for Health 1998:11(2):225-31.

15. Hogeschool van Arnhem en Nijmegen, Faculteit Gezondheidszorg. Multiprofessioneel onderwijs in de gezondheidszorg. Nijmegen: HAN; 1999.

\section{De auteurs:}

A.M.M. Verbeek-Weel, onderwijskundig projectmedewerker, Klinisch Trainingscentrum, Faculteit der Medische Wetenschappen, Katholieke Universiteit Nijmegen.

Prof. dr. J.C.M. Metz, hoogleraar Ontwikkeling en Onderzoek van Medisch Onderwijs, hoofd Klinisch Trainingscentrum, Faculteit der Medische Wetenschappen, Katholieke Universiteit Nijmegen.

\section{Correspondentieadres:}

A.M.M. Verbeek-Weel, Klinisch Trainingscentrum, 224 KTC, Postbus 9101, 6500 HB Nijmegen, tel.: 024 3616330,e-mail: a.verbeek@aig.azn.nl

\section{Summary}

Introduction: In today's complex health care, collaboration of doctors, nurses and other health care workers is one of the most important factors contributing to the quality of care. Problems in communication between different health care professionals and insufficient awareness of one another's expertise and responsibilities form a barrier to high quality health-related services. These problems might be resolved by multiprofessional courses where students from different occupations in health care learn together in order to improve multidisciplinary collaboration and communication. A preliminary study was performed to explore the possibilities and support for multidisciplinary education in health care in the Netherlands.

Method: In the spring of 1998 a literature study was performed, interviews conducted, and a visit paid to the University of Linköping, Sweden.

Results: Multiprofessional education is regarded as a way for students from different educational backgrounds related to health care to learn how to work together as a team. In the Netherlands there is sufficient support for multidisciplinary education to justify experiments to gain more experience with this approach.

Discussion: The report of the exploratory study recommends that the possibilities for developing multiprofessional education in the Netherlands be investigated. A grant was obtained for the development and implementation of a multidisciplinary track for students from medical schools and vocational courses for different health care professions. (Verbeek-Weel AMM, Metz JCM. Multiprofessional education: a feasibility study. Dutch Journal of Medical Education 2001:20(4): 140-146.) 